
Not for reproduction, distribution or commercial use.

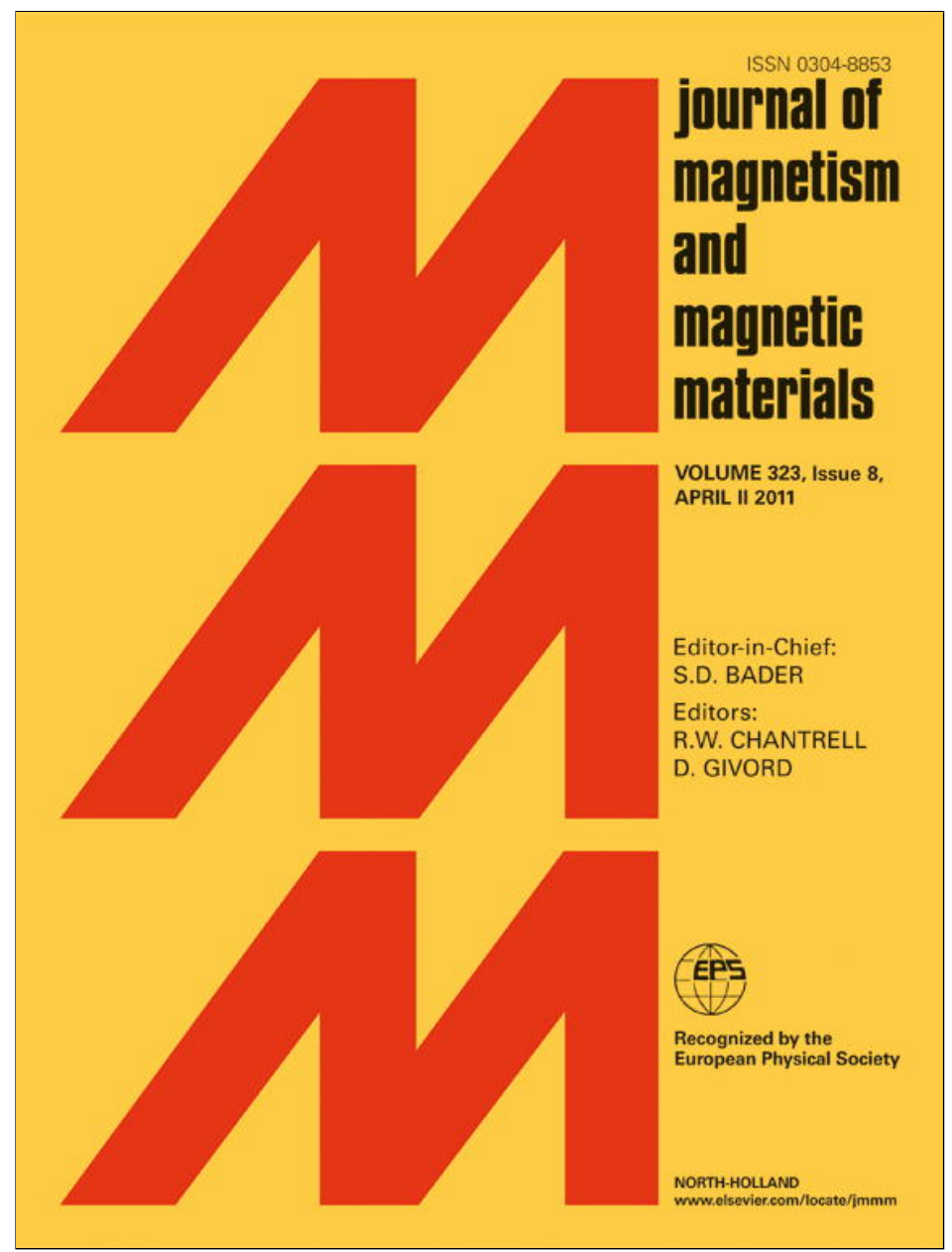

This article appeared in a journal published by Elsevier. The attached copy is furnished to the author for internal non-commercial research and education use, including for instruction at the authors institution and sharing with colleagues.

Other uses, including reproduction and distribution, or selling or licensing copies, or posting to personal, institutional or third party websites are prohibited.

In most cases authors are permitted to post their version of the article (e.g. in Word or Tex form) to their personal website or institutional repository. Authors requiring further information regarding Elsevier's archiving and manuscript policies are encouraged to visit:

http://www.elsevier.com/copyright 


\title{
Magnetic and in vitro heating properties of implants formed in situ from injectable formulations and containing superparamagnetic iron oxide nanoparticles (SPIONs) embedded in silica microparticles for magnetically induced local hyperthermia
}

\author{
Pol-Edern Le Renard ${ }^{\mathrm{a}, *}$, Rolf Lortz ${ }^{\mathrm{b}}$, Carmine Senatore ${ }^{\mathrm{c}}$, Jean-Philippe Rapin ${ }^{\mathrm{d}}$, Franz Buchegger ${ }^{\mathrm{e}}$, \\ Alke Petri-Fink ${ }^{\mathrm{f}}$, Heinrich Hofmann ${ }^{\mathrm{g}}$, Eric Doelker ${ }^{\mathrm{a}}$, Olivier Jordan ${ }^{\mathrm{a}, *}$ \\ a School of Pharmaceutical Sciences, University of Geneva, University of Lausanne, Geneva, Switzerland \\ ${ }^{\mathrm{b}}$ Department of Physics, The Hong Kong University of Science \& Technology, Clear Water Bay, Kowloon, Hong Kong \\ ${ }^{\mathrm{c}}$ Department of Condensed Matter Physics and MaNEP/NCCR, University of Geneva, Geneva, Switzerland \\ d Laboratory of Crystallography, University of Geneva, Geneva, Switzerland \\ e Service of Nuclear Medicine, University Hospital of Lausanne, Lausanne, University Hospital of Geneva, Geneva, Switzerland \\ ${ }^{\mathrm{f}}$ Department of Chemistry, University of Fribourg, Fribourg, Switzerland \\ g Laboratory for Powder Technology, Ecole Polytechnique Fédérale de Lausanne (EPFL), Lausanne, Switzerland
}

\section{A R T I C L E I N F O}

\section{Article history:}

Received 9 November 2010

Available online 7 December 2010

\section{Keywords:}

Magnetically mediated hyperthermia

Superparamagnetism

SPIONS

Microparticles

Composite magnetic microparticles

Injectable formulations

In situ forming implant

Magnetic properties

SQUID

Heating

AMF

Specific power loss

Calorimetry

Pycnometry

Laser diffraction

DFX

TEM

SEM

\begin{abstract}
A B S T R A C T
The biological and therapeutic responses to hyperthermia, when it is envisaged as an anti-tumor treatment modality, are complex and variable. Heat delivery plays a critical role and is counteracted by more or less efficient body cooling, which is largely mediated by blood flow. In the case of magnetically mediated modality, the delivery of the magnetic particles, most often superparamagnetic iron oxide nanoparticles (SPIONs), is also critically involved. We focus here on the magnetic characterization of two injectable formulations able to gel in situ and entrap silica microparticles embedding SPIONs. These formulations have previously shown suitable syringeability and intratumoral distribution in vivo. The first formulation is based on alginate, and the second on a poly(ethylene-co-vinyl alcohol) (EVAL). Here we investigated the magnetic properties and heating capacities in an alternating magnetic field $(141 \mathrm{kHz}$, $12 \mathrm{mT}$ ) for implants with increasing concentrations of magnetic microparticles. We found that the magnetic properties of the magnetic microparticles were preserved using the formulation and in the wet implant at $37^{\circ} \mathrm{C}$, as in vivo. Using two orthogonal methods, a common SLP $\left(20 \mathrm{~W} \mathrm{~g}^{-1}\right)$ was found after weighting by magnetic microparticle fraction, suggesting that both formulations are able to properly carry the magnetic microparticles in situ while preserving their magnetic properties and heating capacities.
\end{abstract}

(c) 2010 Elsevier B.V. All rights reserved.

\section{Introduction}

Induced hyperthermia is a recent therapeutic approach in oncology protocols [1]. It consists of raising the temperature of a target tissue or body region affected by local tumor lesions or even heating the whole body in the case of extensively diffused cancer lesions. These approaches are respectively called local, regional,

\footnotetext{
* Corresponding authors.

E-mail addresses: lerenard.pe@gmail.com (P.-E. Le Renard) olivier.jordan@unige.ch (O. Jordan).
}

and whole-body hyperthermia [2]. Heat affects multiple and complex biological processes, possibly leading to therapeutic benefits. The direct cell killing effect of heat is observed in vitro for temperatures from $42{ }^{\circ} \mathrm{C}$, which corresponds to a threshold for cytotoxicity. Above $45{ }^{\circ} \mathrm{C}$, tissues directly coagulate. Nonetheless, in unfavorable metabolic microenvironments, such as those found in some tumor areas, the threshold can be observed at lower temperatures that are more easily achievable in clinical practice [3-6]. Heat also modulates tumor blood flow to varying extent and sequence, either positively and/or negatively. The vascular response of the tumor differs compared to basal blood flow and to the vascular response of normal tissue, leading to contrasting 
deleterious or beneficial therapeutic effects [6,7]. High tumor blood flow impedes heating through high convective heat dissipation. In contrast, low tumor blood flow can favor heat deposition and concentration due to low convection. This may lead to differential blood flow heat dissipation (decreased in tumors while increased in the surrounding tissues) and a resulting rather selective heat deposition in the tumor lesions [2]. The heat shock proteins, which are crucial to the heat shock response, also present ambivalent features [8]. On one hand, heat shock proteins may be associated with some form of thermotolerance [9-12]. On the other hand, heat shock proteins can also facilitate the unmasking of tumor antigens and their presentation, thereby favoring the immune response to cancer. These mechanisms induced by hyperthermia may thus indirectly lead to an increased anti-tumor response [2,13-17]. In clinical practice, hyperthermia is an accepted adjuvant to reference therapies, mainly chemo- and radio-therapies [18-20]. In these approaches, the physiological effects of heat such as the increased blood supply and oxygen levels are decisive [7,21]. To improve heating, numerous techniques have attempted to manipulate the tumor physiology, among which embolization has been revealed to be useful [4]. The technical limitations of the heat delivery and the poor control of the heat dose are also crucial and impede the effective distribution of cytotoxic temperatures and doses in the target volume. Besides the various physical modalities of delivering heat to solid tumors (infrared, ultrasound, microwave, and radiofrequency techniques), the magnetically induced hyperthermia modality is specifically based on heat dissipation through an interaction with the magnetic component of an alternative magnetic field $[22,23]$. This can be mediated by eddy currents, which dissipate heat in a metallic stent. However, the drawback is that this may lead to the adverse burning of the subcutaneous fat layer. Heating induction can be further mediated by the magnetic relaxations of so-called magnetic seeds [24]. Even at locations deep within the body, tissue areas enclosing magnetic seeds can be heated [25]. Two heating processes are possible. Large ferro- or ferri-magnetic particles dissipate heat through hysteresis effects in the form of domain wall motion, also called hysteresis losses [25-27]. Superparamagnetic nanoparticles allow heating through Brownian or Néel magnetic relaxation [28-32]. As for the latter, the negligible dipole-dipole magnetic interactions with coated particles (the coatings prevent surface interactions) allow for the safe injection in human bodies without the risk of adverse aggregation [33]. Regarding the biocompatibility, coated superparamagnetic iron oxide nanoparticles (SPIONs) are approved for human use [34]. Entrapping SPIONs in silica microparticles leads to superparamagnetic seeds with three advantages: (i) inter-particle coupling through SPION-dipole interactions is avoided, (ii) intrinsic superparamagnetism, i.e., Néel relaxation, is favored, and (iii) the rheological behavior of the microparticles incorporated into the liquid formulations allows for high syringeability. We previously developed formulations incorporating these (SPION)-silica composite microparticles on the basis of embolizing formulations. Although it is liquid before injection, the vehicle converts into a solid matrix in the injected tissue, forming a so-called implant that entraps the microparticles [35]. With this confined in the solid tumor, we can demonstrate the efficiency of heating in an animal model and the potential for local hyperthermia associated with such a formulation [36]. As for magnetically induced hyperthermia modalities, heating primarily relies on the magnetic properties of the injected materials. From a pharmaceutical standpoint, it is important to ensure the preservation of the magnetic properties in the final implant as well as the heating capacity under an alternating magnetic field. In the present work, we therefore characterized by means of a Superconducting Quantum Interference Device magnetometer (SQUID) the static magnetic properties of the SPION-silica composite microparticles and of the implants formed under conditions mimicking the in vivo environment. Heating capacity was measured through power losses under alternating magnetic field. These characterizations were performed with increasing magnetic microparticle concentrations in the implants.

We focused these investigations on two formulations that had previously demonstrated high syringeability and proper intratumoral distribution, both being essential criteria for therapeutic use [35]. One was based on alginate hydrogels that were cross-linked by co-injectable $\mathrm{Ca}^{2+}$. The other formulation was based on a water insoluble polymer (poly(ethylene-co-vinyl alcohol), EVAL) organogel, which forms in situ an implant through precipitation after organic solvent exchange with water.

\section{Experimental details}

\subsection{Magnetic microparticles}

Silica micron-sized particles embedding SPIONs were synthesized as previously described [37]. Briefly, organic precursors of silica and iron chloride were mixed. The sol-gel precipitation of silica was triggered by soft heating. Then, iron oxide precipitation was carried out, and the gel porosity helped the nucleation of iron oxide in the expected magnetite phase, which was black. Thereafter, a second heating at a higher critical temperature $\left(800{ }^{\circ} \mathrm{C}\right)$ ensured magnetite phase (black color bulk) oxidation to form the ferrimagnetic maghemite phase (tetragonal cell unit, red-brown color bulk), which could be considered as fully oxidized magnetite (c.a. $2 \mathrm{Fe}_{3} \mathrm{O}_{4}+0.5 \mathrm{O}_{2} \rightarrow 3 \gamma \mathrm{Fe}_{2} \mathrm{O}_{3}$ [38]), while preserving maghemite from further transformation into hematite $\left(\alpha \mathrm{Fe}_{2} \mathrm{O}_{3}\right.$, rhombohedral and canted ferromagnetic of red color bulk) [39]. The bulk maghemite-silica composite matrix resulting from this process was then ground to form microparticles. A first coarse powder was obtained by ball milling. This coarse powder was then submitted to wet attrition to obtain a finer powder made of microparticles. Inspection of the resulting microparticles by eye and under microscope showed a reddish-brown color, more reddish than the bulk reference color, with respect to the color plates in Ref. [40]. With this reference, and further taking into account the variation in color with particle size, the slightly reddish-brown color of our powder likely excludes the possibility of magnetite. In contrast, commercial samples made of a similar silica matrix containing nanoscaled crystallites of magnetite (as confirmed by X-ray) display a black color very close to the black color of bulk magnetite [40]. These organoleptic characteristics likely exclude the possibility that our microparticles contain nanoscaled magnetite crystallites. Finally, this magnetic seed powder contained $19.6 \%$ iron oxide by mass, as determined by redox titration after silica matrix dissolution under acidic conditions.

\subsection{Characterization methods}

\subsubsection{Pycnometry and size analysis by laser diffraction}

We used a helium pycnometer Accupyc 1330 (Micromeritics, Aachen, Germany) to determine the magnetic microparticle density and specific volume. Calibration and sample measurements were performed in a high accuracy mode. The size distribution of the microparticle powder sample dispersed in water was measured by laser diffraction with a Mastersizer apparatus (Malvern, Worcestershire, UK). We set the particle density to 2.39 (as previously determined by pycnometry determination). The microparticle refractive index (1.67) was calculated by the weight ponderation of the refractive index of sol-gel silica microspheres (1.42 [41]) and maghemite (2.69) that compose the particle. An imaginary part (0.1) of the refractive index that corresponds to $10 \%$ absorption was 
set according to instrument guidelines, given the opaque brown color of the raw powder sample by eye. The refractive index of the dispersion medium, i.e., water, was set at 1.33 . The powder sample was added under stirring in the module dedicated to wet sample analysis, typically at $900 \mathrm{rpm}$, up to an opacity degree of about $20 \%$ (corresponding volume concentration of $0.014 \%$ ).

\subsubsection{X-ray diffraction $(X R D)$}

Samples were examined by XRD with a BRUKER D8 diffractometer using cupper $K_{\alpha 1}$ radiation $(\lambda=1.54056 \AA$ ). Diffractograms were recorded in the range of $10<2 \theta<100$ with a step of $0.014^{\circ}$, and the total data collection time was approximately $12 \mathrm{~h}$. Data were analyzed using the FullProf Suite [42].

\subsubsection{Transmission electronic microscopy (TEM)}

Formvar-coated grids were made hydrophilic by residual gas ionization. Magnetic microparticles were suspended in water at $1 \%$ $\mathrm{w} / \mathrm{V}$ and vigorously shaken, and $5 \mu \mathrm{L}$ were allowed to deposit on the grid for $30 \mathrm{~s}$ before removing the excess of suspension. The observations were performed using a Tecnai G2 TEM (FEI, The Netherlands), with a $\mathrm{LaB}_{6}$ cathode, at $160 \mathrm{kV}$.

\subsubsection{Scanning electron microscopy and energy-dispersive $X$-ray spectroscopy (SEM-EDX)}

Magnetic microparticles were coated by the sputter deposition of gold under $0.05 \mathrm{mbar}$ of argon for $5 \mathrm{~min}$ at a $10 \mathrm{~mA}$ current intensity. The SEM was a LEO 438 (Zeiss Carl, France). The module for EDX analysis was from Gloore Instrument AG (Switzerland).

\subsection{Formulation preparation and in vitro implant formation}

\subsubsection{Liquid formulation preparations}

2.3.1.1. Polymer solution preparations for the organogel formulation. A poly(ethylene-co-vinyl alcohol) (EVAL E-105 B Europe, Zwijndrecht, Belgium) with $44 \mathrm{~mol} \%$ ethylene (ensuring flexibility), which is clinically used for embolization (Onyx ${ }^{\circledR}$ ), was dissolved at $8 \% \mathrm{w} / \mathrm{V}$ in dimethyl sulfoxide (DMSO, Acros Organics, Basel, Switzerland) at $50{ }^{\circ} \mathrm{C}$. The density was measured using Mohr's balance, $d_{\mathrm{H}_{2} \mathrm{O}, 0^{\circ} \mathrm{C}}^{2{ }^{\circ} \mathrm{C}}=1.11089$. The magnetic composite silica microparticles were suspended using vigorous vortexing and sonication.

2.3.1.2. Polymer solution preparations for the hydrogel formulation. Low viscosity sodium alginate (Fluka, Buchs, Switzerland, 100 to $200 \mathrm{mPa}$ s for $1 \%$ aq., 65-75\% glucuronic acid) was dissolved in ultrafiltrated water at $2 \% \mathrm{w} / \mathrm{V}$. The density was measured using Mohr's balance at $23{ }^{\circ} \mathrm{C}, d_{\mathrm{H}_{2} O, 0^{\circ} \mathrm{C}}^{2{ }^{\circ} \mathrm{C}}=1.01775$. The magnetic composite silica microparticles were suspended using vigorous vortexing and sonication.

2.3.1.3. Magnetic microparticle incorporation. Hydrogel and organogel formulations were labeled as $\mathrm{H}-x x$ and $\mathrm{O}-x x$, respectively, where the number $x \mathrm{x}$ refers to the mass percentage of the magnetic microparticles added to a given volume of liquid polymer solution, i.e., $5,1020,40,60,80$, and $100 \% \mathrm{w} / \mathrm{V}$. The mass fractions will constantly be restated for clarity, but attention should be paid to the system considered: liquid implant formulation before gelation or wet implant after gelation.

\subsubsection{In situ formation of implants}

All implants were prepared in vitro, mimicking the in vivo injection intended for the treatment of soft tissue solid tumors. The syringe and the receiving flask were weighted to quantify the experimental variation and allow for reliable composition determination. For full settling, we let the implant rest for $5 \mathrm{~h}$ in the flask after injection. The hydrogel formulation based on alginate was injected in a solution of $\mathrm{CaCl}_{2}$ (Fluka, Buchs, Switzerland) at $25 \mathrm{mM}$ in ultrafiltrated water. This acceptably mimics the in vivo co-injection, during which mixing with the ionic cross-linker $\left(\mathrm{Ca}^{2+}\right)$ solution occurs within the needle, not in situ. This allows for a more accurate determination of the injected masses. The organogel formulation was injected in water, allowing polymer precipitation and magnetic silica microparticle entrapment to form in situ in the implant. A $27 \mathrm{G}$ needle was used for microparticle concentrations below $40 \% \mathrm{w} / \mathrm{V}$, and a $19 \mathrm{G}$ was used on reaching this concentration. The uncertainty in the implant mass, measured by weight loss of the syringe, in parallel with the weight gain of the receiving flask, was below $0.8 \%$ when comparing the mass of the harvested soaked implant. The resulting in-situ-formed implants were harvested, excess liquid was drained while preserving the soaked state, and this was submitted for further magnetic characterization after weighing.

\subsection{Superconducting quantum interference device (SQUID)}

Magnetic properties were characterized using a Superconducting Quantum Interference Device (SQUID), model MPMS2, Quantum Design, INC (San Diego CA, USA). We investigated the magnetic properties of the implants in a field and temperature range relevant for their clinical use at $310 \mathrm{~K}$ (matching physiologic body temperature at $37{ }^{\circ} \mathrm{C}$ ) and between -39.8 and $39.8 \mathrm{kA} \cdot \mathrm{m}^{-1}(-500$ to $500 \mathrm{Oe}$ ), which may appear limited compared to other fundamental studies, but it more closely reflects the $0-9.55 \mathrm{~A} \cdot \mathrm{m}^{-1}$ (0-120 Oe) range that is acceptable for hyperthermia treatment. Soaked implants were sealed in a sample holding tube so that soaking was preserved. Control powder was sealed dry in a sample holding tube. The details of the sample compositions are shown in Table 1 . The symmetry of the $M-H$ loop was adjusted by subtracting $X$ offset, corresponding to the remnant field from the magnetic field strength $(H)$. The diamagnetic background was deduced by dividing the magnetization value $(M)$ by the slope of the end region of the curve showing no hysteresis.

\subsection{Heating capacities under an alternative magnetic field}

2.5.1. Alternative magnetic field (AMF) generation and thermometry

The field generator (TIG 2.5, Hüttinger Elektronik $\mathrm{GmbH}$, Freiburg, Germany) consisted of an alternating current generator feeding the coil inductor (the internal and external diameters and length of the horizontal coil were 54,64 , and $46 \mathrm{~mm}$, respectively). With a small pick-up coil calibrated using a teslameter, we found a linear relationship between the magnetic field amplitude at $141 \mathrm{kHz}$ and the generator peak-to-peak voltage. The current intensity was adjusted to impose the voltage corresponding to a $12 \mathrm{mT}$ induction. The sample placed in a cylindrical plastic holder $(0.4 \mathrm{~cm}$ in diameter and $3 \mathrm{~cm}$ in height) was isolated from the surroundings by a polystyrene foam chamber fitted within the coil. The surface temperature of the sample was monitored with a fluoroptic thermometer (Luxtron, Santa Clara CA, USA) using $200 \mu \mathrm{m}$ diameter fiber optic probes. The device reported temperatures once every second with a $0.1{ }^{\circ} \mathrm{C}$ accuracy. A one-point calibration at $20.0{ }^{\circ} \mathrm{C}$ was performed. Data were acquired using Physitemp software (Luxtron, Santa Clara CA, USA). The implants were prepared as described in Section 2.3.2. With this, we determined the specific loss power (SLP) by two methods: Methods $\mathrm{A}$ and $\mathrm{B}$.

\subsubsection{Method A of SLP determination}

The wet implant was placed in an insulated tube. The thermometric probe was inserted into the implant periphery. The tube was 
Table 1

Sample details concerning the magnetic characterization by SQUID.

\begin{tabular}{|c|c|c|c|c|c|c|c|c|c|c|}
\hline Formulation & $\begin{array}{l}\text { Constituting } \\
\text { polymer in } \\
\text { the mother } \\
\text { solution }\end{array}$ & $\begin{array}{l}\text { Polymer } \\
\text { mass fraction } \\
\text { in the mother } \\
\text { solution }\end{array}$ & $\begin{array}{l}\text { Polymer mass } \\
\text { fraction in the } \\
\text { liquid } \\
\text { formulation }\end{array}$ & $\begin{array}{l}\text { Magnetic } \\
\text { microparticle } \\
\text { mass fraction in } \\
\text { the liquid } \\
\text { formulation }\end{array}$ & $\begin{array}{l}\text { Mean mass of the } \\
\text { liquid formulation } \\
\text { injected for } \\
\text { implantation (g) }\end{array}$ & $\begin{array}{l}\text { Variation } \\
\text { between } \\
\text { weighs in } \\
\text { mass } \\
\text { percentage }\end{array}$ & $\begin{array}{l}\text { Weight } \\
\text { of the } \\
\text { wet } \\
\text { implant } \\
\text { (g) }\end{array}$ & $\begin{array}{l}\text { Weight of } \\
\text { the } \\
\text { desiccated } \\
\text { implant }(\mathrm{g})\end{array}$ & $\begin{array}{l}\text { Mean } \Delta T \\
\text { during 2- } \\
\text { min in } \\
\text { AMF }(K)\end{array}$ & $\begin{array}{l}\text { Standard } \\
\text { variation of } \\
\Delta T \text { during } \\
2-\text { min in } \\
\text { AMF }(K)\end{array}$ \\
\hline O-05 & EVAL & 0.069 & 0.066 & 0.038 & 1.012 & 0.040 & 0.714 & 0.104 & 0.678 & 0.203 \\
\hline $0-10$ & EVAL & 0.069 & 0.064 & 0.079 & 1.041 & 0.019 & 0.753 & 0.140 & 1.350 & 0.346 \\
\hline $0-20$ & EVAL & 0.069 & 0.059 & 0.143 & 1.121 & 0.036 & 0.896 & 0.227 & 3.827 & 0.808 \\
\hline $0-40$ & EVAL & 0.069 & 0.052 & 0.248 & 1.237 & 0.016 & 1.083 & 0.370 & 5.956 & 0.501 \\
\hline $0-60$ & EVAL & 0.069 & 0.046 & 0.329 & 1.328 & 0.038 & 1.166 & 0.508 & 10.782 & 1.514 \\
\hline $0-80$ & EVAL & 0.069 & 0.042 & 0.392 & 0.635 & 0.063 & 0.579 & 0.276 & 6.249 & 1.323 \\
\hline $0-100$ & EVAL & 0.069 & 0.037 & 0.460 & 1.090 & 0.073 & 1.034 & 0.366 & 10.119 & 0.561 \\
\hline $\mathrm{H}-05$ & Alginate $\mathrm{Na}$ & 0.020 & 0.019 & 0.042 & 0.950 & 0.105 & 0.722 & 0.058 & 0.761 & 0.351 \\
\hline $\mathrm{H}-10$ & Alginate $\mathrm{Na}$ & 0.020 & 0.018 & 0.091 & 1.037 & 0.617 & 0.902 & 0.105 & 1.322 & 0.153 \\
\hline $\mathrm{H}-20$ & Alginate $\mathrm{Na}$ & 0.020 & 0.017 & 0.152 & 0.553 & 0.887 & 0.504 & 0.095 & 1.142 & 0.602 \\
\hline $\mathrm{H}-40$ & Alginate $\mathrm{Na}$ & 0.020 & 0.015 & 0.262 & 0.746 & 0.496 & 0.740 & 0.206 & 4.529 & 0.237 \\
\hline $\mathrm{H}-60$ & Alginate $\mathrm{Na}$ & 0.020 & 0.013 & 0.348 & 1.211 & 0.025 & 1.331 & 0.427 & 8.215 & 0.462 \\
\hline $\mathrm{H}-80$ & Alginate $\mathrm{Na}$ & 0.020 & 0.012 & 0.417 & 1.048 & 0.114 & 1.147 & 0.435 & 9.639 & 0.964 \\
\hline $\mathrm{H}-100$ & Alginate $\mathrm{Na}$ & 0.020 & 0.011 & 0.477 & 0.796 & 0.000 & 0.870 & 0.538 & 10.430 & 1.408 \\
\hline
\end{tabular}

placed within the coil for magnetic induction by AMF. Experiments were performed in triplicate, except for $\mathrm{H}-40$, for which only duplication was realized. We switched on the generator at $t=0 \mathrm{~s}$. We recorded the temperature from $t=0$ to at least $t=60 \mathrm{~s}$. The derivative of the temperature by time $\left({ }^{\circ} \mathrm{C} / \mathrm{s}\right)$ was smoothed by the moving averaged widow method on five points. We then determined the maximum of this derivative occurring within the first $20 \mathrm{~s}$. This maximum was considered to be the best approximation of the "adiabatic" specific heat losses of the boundary conditions. We then calculated the corresponding heat rate. For this, we neglected the polymer mass fraction within the wet sample (this is already low in the formulation, and it decreases with increase in magnetic microparticle fraction and after implant formation in water, with a mean polymer mass fraction in wet implants of $0.38 \pm 0.36 \%)$. We took into account the silica $\left(\mathrm{SiO}_{2}\right)$ mass present in the sample, as determined by injection weighing. Although negligible at low concentrations such as $5 \% \mathrm{w} / \mathrm{V}$, this fraction is of increasing importance in concentrated formulations. In the same way, we took into consideration the iron oxide $\left(\mathrm{Fe}_{2} \mathrm{O}_{3}\right)$. Finally, the most important constituent to contribute to the heat capacity of the whole implant was the water $\left(\mathrm{H}_{2} \mathrm{O}\right)$ mass present in the sample, which was determined by desiccation. The standard (i.e., at $25^{\circ} \mathrm{C}$ ) heat capacities in $\mathrm{J} \cdot \mathrm{K}^{-1} \cdot \mathrm{g}^{-1}$ were $0.739,0.651$, and 4.18 for $\mathrm{SiO}_{2}, \mathrm{Fe}_{2} \mathrm{O}_{3}$, and $\mathrm{H}_{2} \mathrm{O}$, respectively. Method $\mathrm{A}$ thus allowed us to calculate the total heat production rate and the specific loss power (SLP) as normalized to the weight of the iron oxide in $\mathrm{W} / \mathrm{g}$ of iron oxide.

\subsubsection{Method B of SLP determination}

This method was adapted from Bretcanu et al. [43]. It consisted of placing the wet implant, formed in vitro as previously described but with an adapted size, into an insulated vial in contact with $4 \mathrm{~mL}$ of additional water. This vial was then placed in the coil of the AMF inducer, to be submitted to a 2 min AMF induction. The initial temperature was recorded. After the $2 \mathrm{~min}$ AMF induction, the final temperature was determined, with the vial rapidly shaken to ensure a homogeneous heat distribution. This allowed us to determine the $\Delta T$ of water during $2 \mathrm{~min}$ of heating by AMF induction, which is relevant for the in vivo conditions, where the solid tumor tissues can be approximated by certain water volumes. Here, because the major mass fraction in the system is water, which has the highest heat capacity, the other components of the implant can be neglected for calorimetric considerations.

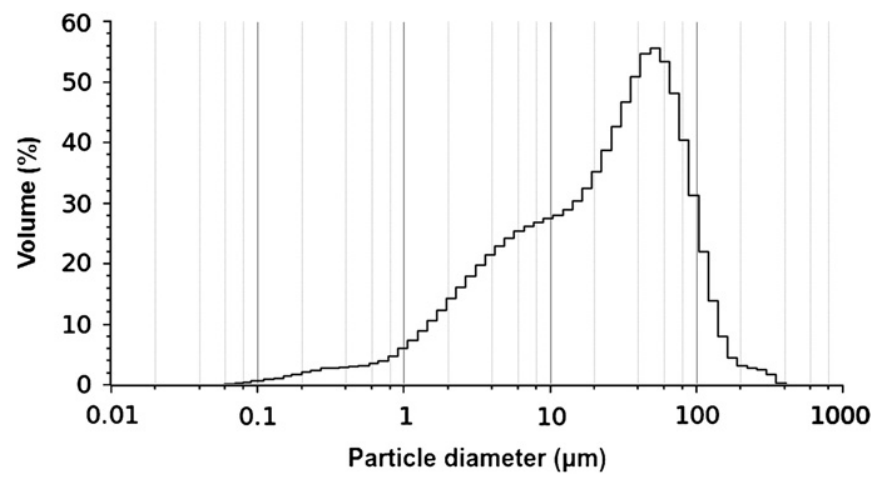

Fig. 1. Size distribution of our particle powder sample by laser diffraction in a water dispersion. The stirring speed applied here was $960 \mathrm{rpm}$. A lower stirring speed may hinder the second-mode population (centered at $40 \mathrm{~m}$ ) by sedimentation of the largest particles (see Section 3.1.1).

\section{Results and discussion}

\subsection{Structural properties of the SPION-silica composite microparticles}

The densities of hematite, magnetite, and maghemite are 5.26, 5.18 , and $4.87 \mathrm{~g} \cdot \mathrm{cm}^{-3}$, respectively [39]. The density of the particles determined by pycnometry was $2.391 \pm 0.001 \mathrm{~g} \cdot \mathrm{cm}^{-3}$, i.e., a specific volume of $0.418 \pm 0.002 \mathrm{~cm}^{3} \cdot \mathrm{g}^{-1}$. The powder discharge density, i.e., the bulk powder specific volume, was $0.3329 \mathrm{~g} / \mathrm{cm}^{3}$. This corresponds roughly to the intra- plus extragranular porosity of the discharged powder, i.e., the uncompressed powder, of $84 \%$.

\subsubsection{Size distribution analysis by laser diffraction}

The powder dispersion in the water analysis by laser diffraction revealed a mean diameter $\operatorname{Dv}(0,5)$ of $23.6 \mu \mathrm{m}$ and a partially overlapping bimodal size distribution, as shown in Fig. 1 . The size distribution corresponding to the first mode, which can be considered as log-normal or normal, is characterized by a large span and is centered around a volume diameter of $10 \mu \mathrm{m}$. The size distribution corresponding to the second mode appears to be lognormal, sharper, and centered on a volume diameter of $40 \mu \mathrm{m}$. Accurate measurement requires rapid stirring above $900 \mathrm{rpm}$, i.e., well above the 300-rpm threshold at which sedimentation hinders 
the $40-\mu \mathrm{m}$ mode subpopulation. This bimodal distribution likely results from the two-step attrition processes of the bulk composite matrix, leading to these microparticles. The first step, consisting of milling, leads to particles with diameters corresponding to the largest mode. The second step, a wet attrition, reduces the resulting coarse powder yield to the finest particles corresponding in diameter to the first observed mode.

\subsubsection{Particle analysis by TEM}

The observations of the magnetic microparticles by transmission electron microscopy are illustrated in Fig. 2. The silica matrix is of intermediary electrodensity. The areas of lowest electrodensity correspond to voids, confirming the previously discussed porosity and suggesting the microporosity, and partially mesoporosity, well known for the sol-gel preparation method. SPIONs of the highest electrodensity appear to be trapped in the mesopores. This confirms the role for mesopores in controlling nucleation and growth during subsequent thermal treatment.

\subsubsection{Particle analysis by SEM-EDX}

High-magnification observations of a powder sample of magnetic microparticles by scanning electron microscopy are illustrated in Fig. 3. One-micrometer microparticles can be discerned. These microparticles tend to aggregate in the dry powder sample. The larger rough structures, c.a. $10 \mu \mathrm{m}$, are likely reversible aggregates of microparticles. These reversible aggregates could, to some extent, widen the volume diameter distribution of the first-mode particle subpopulation observed by laser diffraction size analysis. In contrast, the smooth larger structures with regular edges (c.a. $10 \mu \mathrm{m}$ ) could correspond to subsisting milled particles, as already evoked above. With regard to particle size, one should keep in mind that energy-dispersive X-ray spectroscopy, EDX, allows for the analysis of the electronic transition occurring after incident electrons have interacted with the atoms of the sample

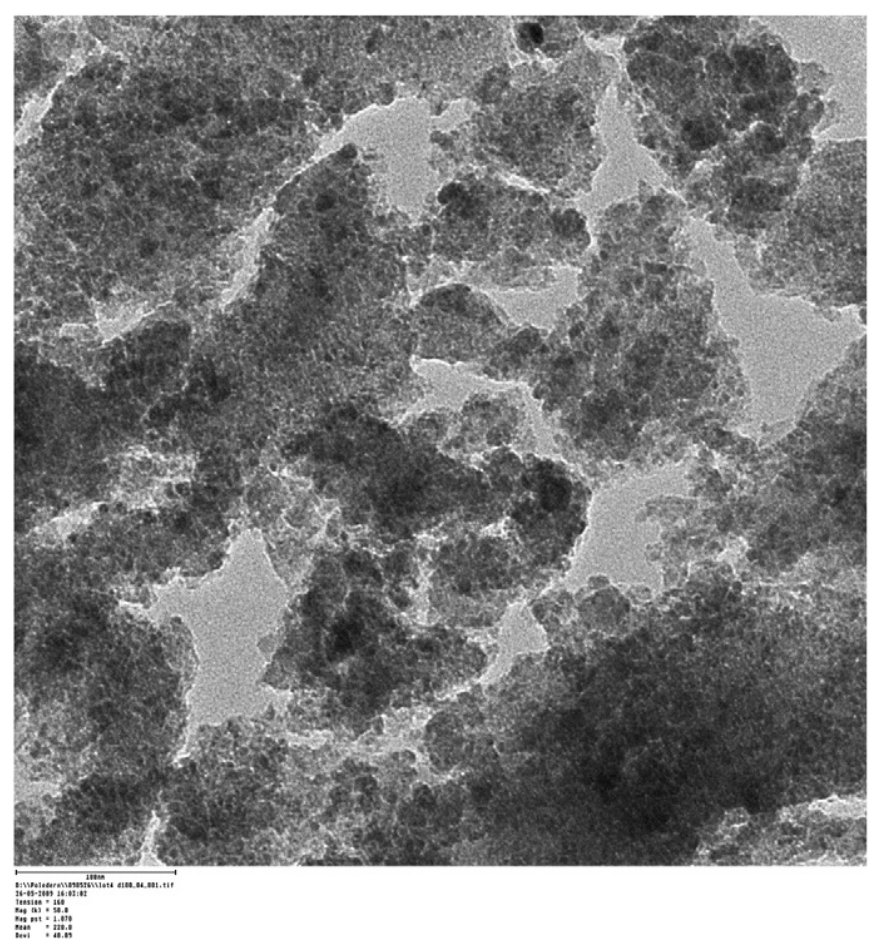

Fig. 2. Transmission electron microphotograph of magnetic microparticles used as magnetic seeds for heating under AMF. The microparticles consist of SPIONs of high electrodensity (dark spots) entrapped in a silica matrix of lower electrodensity (gray areas surrounding the dark spots). The lightest gray areas correspond to voids.

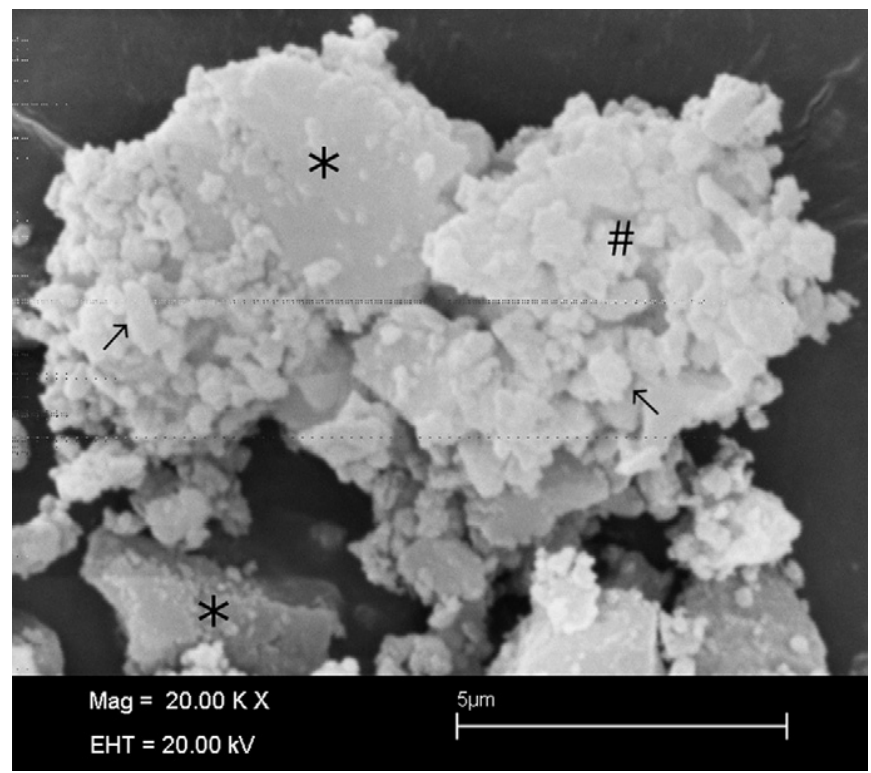

Fig. 3. SEM image illustrating the characteristics of the magnetic seed powder samples prepared by milling bulk nancomposite and magnetic matrix followed by wet attrition. The arrows indicate two particles of the most numerous subpopulations with diameters in the range of $1 \mu \mathrm{m}$, as expected from the last step of wet attrition. These microparticles agglomerate into larger rough structures with sizes ranging from 5 to $10 \mu \mathrm{m}$ (\# mark). These aggregates are likely reversible and are not expected to be found after dispersion in liquids, which notably contain polymers able to act as surfactants. The star marks indicate large structures with largest dimensions of $5-10 \mu \mathrm{m}$ but with smooth facets and regular edges by contrast.

(roughly $1 \mu \mathrm{m}$ in depth from the sample surface) and caused an atom electron to be ejected. When an electron of the K-layer is ejected, an electron of the L-layer replaces this electron and produces a $\mathrm{K}_{\alpha}-\mathrm{X}$-ray that is specific to the atom. The calculation of the iron oxide content based on the hypothesis of sole $\mathrm{Fe}_{2} \mathrm{O}_{3}$ and $\mathrm{SiO}_{2}$ compounds leads, for a representative point, to an iron oxide proportion of $23.7 \pm 0.1 \%$, close to that found by redox titration (19.6\%). Other points revealed highly oxidized compounds that could not be analyzed.

\subsubsection{Crystalline structure by XRD}

The X-ray powder diffractogram of magnetic microparticles is shown in Fig. 4. The rise in intensity at small angle (from $2 \theta$ values of $10-25^{\circ} \mathrm{C}$ ) is typical of the amorphous silica phase. Analyzing the Bragg position of the reflexions, two structural models for $\mathrm{Fe}_{x} \mathrm{O}_{y}$ could fit the obtained data: magnetite and maghemite. Because the crystallinity of the present sample does not reach the large levels of bulk samples, Rietveld refinement performed with both structural types cannot be determined with certainty, which model is the correct one, even if the maghemite one fits slightly better (Fig. 4). Of note, the peak intensity is relatively low and appears limited compared to the background with respect to bulk maghemite. This could be ascribed to the nanometric scale of the maghemite crystallites within the silica matrix. This could also partly be explained by the presence of a fraction of amorphous iron oxide phase, which is probably limited to the surface layer at the boundary of the crystallite lattice.

\subsubsection{Magnetic properties by SQUID}

The measurement of bulk magnetic microparticle powder samples gives the typical curve of a soft magnetic material displayed in Fig. 5 [44], with low coercivity $\left(H_{\mathrm{C}} \sim 273.7 \mathrm{~A} \mathrm{~m}^{-1}\right.$ or $3.44 \mathrm{Oe})$ and retentivity $\left(B_{\mathrm{R}} \sim 1.2 \times 10^{-1} \mathrm{~A} \cdot \mathrm{m}^{2} \cdot \mathrm{kg}^{-1}\right.$ or emu per gram) of the magnetic seeds. Of note, in the case of soft magnetic materials, the difference between the intrinsic coercivity and the 
coercivity is negligible. Also, the gray dashed straight line in Fig. 5 reflects the slope of the curve after hysteresis closure. This slope is classically described when saturation is reached during a hysteresis measurement, i.e., for a major hysteresis curve. For large magnetic fields, the hysteresis closes, and the magnetic induction, $B$, and the magnetization, $M$, are saturated (the saturation induction $B_{S}$ should be distinguished from saturation magnetization $M_{\mathrm{S}}$ ). $M$ is thus constant. The linear increase in the induction, $B$, is then explained as the partial conversion of the magnetic field $H$ into $B$. Nevertheless, because of the superparamagnetic behavior and with regards to the literature, it is worth pointing out the possibility

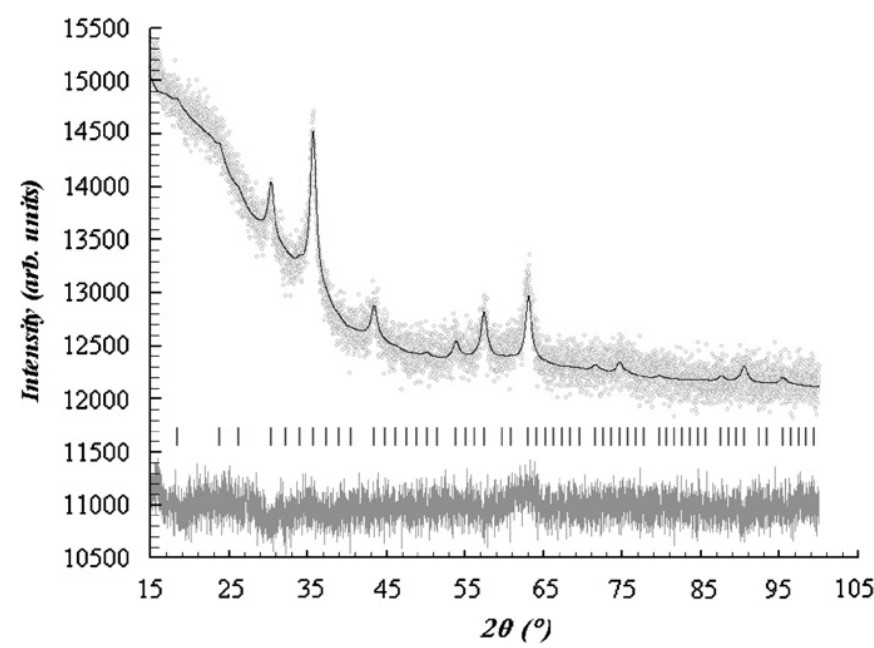

Fig. 4. X-ray powder diffraction characterization. The observed intensity of diffraction by the magnetic microparticle powder is depicted by the open light gray open circled dots (upper). The diffractogram calculated using the Rietveld refinement for maghemite with Fullprof [42] is superimposed as the continuous black line. Reference $2 \theta$ values corresponding to the Bragg diffraction rays for maghemite are displayed as dark gray vertical bars below (middle). The difference between the observed and calculated values of diffraction intensity is displayed below in the lighter gray line. that saturation is not effectively reached here and considering that such characteristics can be displayed by minor hysteresis curves in this specific case. Classically, the slope of $\mathrm{d} B / \mathrm{d} H=\mu_{\mathrm{r}} \mu_{0}=\mu$ tends beyond $B_{S}$ toward $\mu_{0}$ in SI units or 1 in $S$ units, as the permeability $\mu(\mathrm{CGS})$ or $\mu_{\mathrm{r}}(\mathrm{SI})$ approaches unity as $H$ approaches infinity. However, the slope of the line beyond hysteresis closure does not normally appear to be unity because the $B$ and $H$ scales are quite different [38]. Permeability can be evaluated in our case to have a value of $0.32 / \mathrm{kg}$ of magnetic seeds in the SI system or $3.87 \times 10^{-3} / \mathrm{g}$ of magnetic seeds in the CGS system. Furthermore, in our case, both the diamagnetic silica matrix and the paramagnetic contributions of the iron oxide phase itself could contribute to the signal. We opted for the deduction in this permeability component to focus on the intrinsic induction (also called ferric induction) of the magnetic microparticles and to attain $M$. This results in the dashed hysteresis loop of Fig. 5. This procedure does not change $B_{R}$ (and $M_{R}$ ) and only raises the value of the still very low coercive field to $307 \mathrm{~A} \cdot \mathrm{m}^{-1}$ (3.86 Oe). In the model of fundamental studies but with respect to a much more limited field range, this hysteresis loop thus evidences a saturation of the ferrimagnetic phase, apparently at a field larger than $23.9 \mathrm{kA} \cdot \mathrm{m}^{-1}$ (300 Oe). It is first important to note that saturation will thus never be reached in the clinical range of 0-9.5 $\mathrm{kA} \cdot \mathrm{m}^{-1}(0-120 \mathrm{Oe})$ for the AMF induction of hyperthermia. The apparent saturation associates with a maximal intrinsic induction (corresponding to the so-called magnetization at saturation, $\sigma_{\mathrm{s}}$, when the saturation is ascertained) of about $2.5 \mathrm{~A} \mathrm{~m}^{2} / \mathrm{kg}$ of magnetic seeds (or $2.5 \mathrm{emu} / \mathrm{g}$ of magnetic seeds), which translates to $12.8 \mathrm{~A} \mathrm{~m}^{2} / \mathrm{kg}$ of iron oxide. These values for materials with particular micro- and nano-structures are classically compared with the reference experimental values for bulk materials to find a landmark (i.e., for maghemite: $>159 \mathrm{kA} \mathrm{m}^{-1}$ (2000 Oe) for the saturation field, and $\sigma_{\mathrm{S}}=60-80 \mathrm{~A} \mathrm{~m}^{2} / \mathrm{kg}$ of bulk maghemite at $300 \mathrm{~K}$ [40]). This comparison is only indicative and should be cautiously criticized in the case of complex microstructures. It is known that the saturation magnetization is highly dependent on magnetic particle interactions with the matrix in the case of composite materials and on magnetic particle concentrations

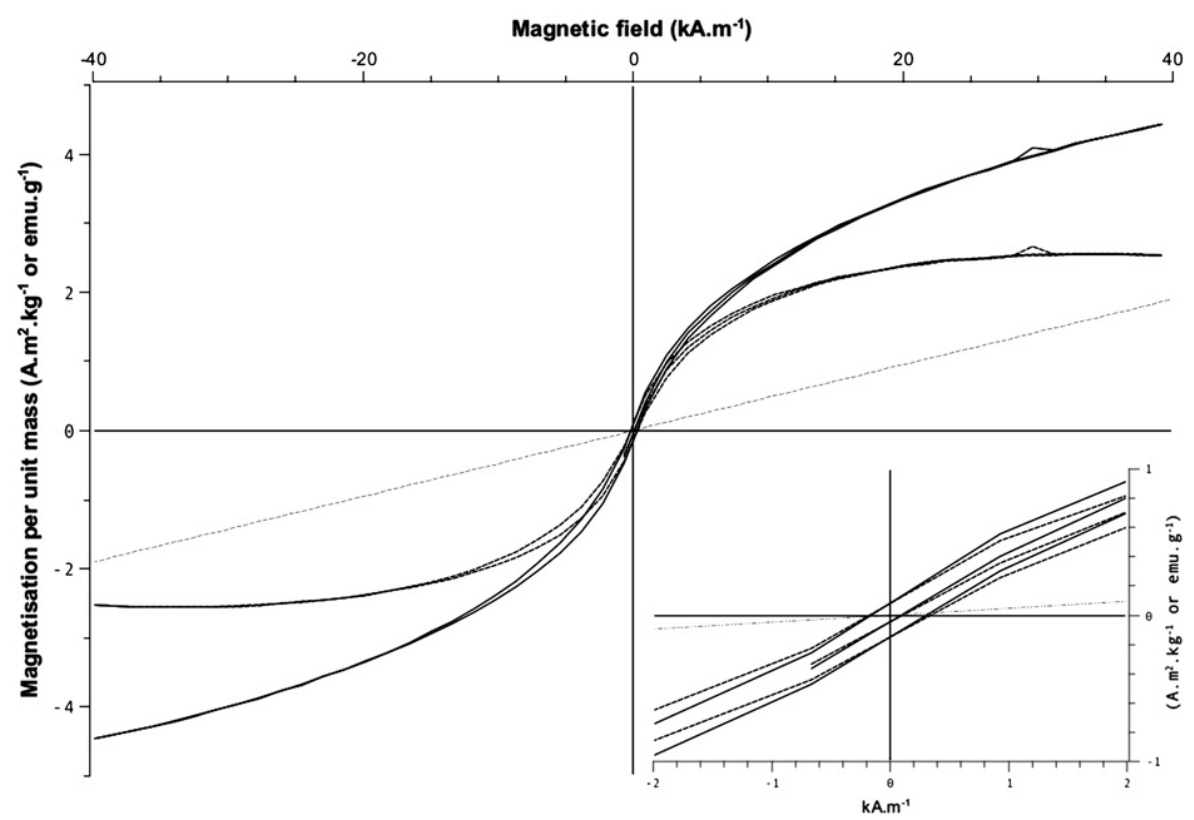

Fig. 5. Magnetization curve of raw magnetic microparticles, control sample c, as determined by the SQUID loop measurement, characteristics of the superparamagnetic behavior (sample mass of $8 \mathrm{mg}$ ). The directly obtained curve is depicted by a continuous black line. Shown by a straight dashed gray line are the paramagnetic contributions that were calculated. The dashed black line corresponds to the curve after the deduction of these paramagnetic contributions. The inset on the bottom right details these curves at small magnetic induction, as well as the offset applied to compensate for the small remnant field within this range. This reveals a very small hysteresis, characteristic of a largely superparamagnetic population of particles with a very low proportion of particles that are still blocked. 
within the matrix, concentrations which govern the interactions and coupling between particles $[45,46]$. In our case, the iron oxide concentration is relatively low and thus is not problematic. Also, the specific saturation magnetization decreases notably with increase in specific surface area [47] and is influenced by the particle morphology [48]. The saturation magnetization of maghemite nanoparticles embedded in a silica matrix was indeed demonstrated to decrease drastically when the temperature increased from 77 to $300 \mathrm{~K}$ [49]. Although not clearly understood, this appears to be a consequence of the already-mentioned surface effects, prominent at the nanoscale, due to the paramagnetic external layer surrounding the ferrimagnetic core of the maghemite nanoparticles, resulting in a decreased magnetic diameter [50-52]. Because the magnetic moment is determined exclusively by the ferrimagnetic core where the spins are aligned as a result of the super-exchange interaction, the spontaneous magnetization consequently decreases [49]. In comparison, the variation in the saturation magnetization in bulk maghemite appears to be very limited, a seven-fold factor less over the same temperature range (the Curie point of maghemite, $T_{\mathrm{c}}$, can be interpolated on the order of $1123 \mathrm{~K}$ or $850{ }^{\circ} \mathrm{C}$ if it would not give prior temperature decomposition [38]). It can thus be hypothesized that the magnetic diameter and saturation induction of the present nanocomposite magnetic seeds will be even lower at the investigated temperature of $310 \mathrm{~K}$. This most likely explains why the reported saturation magnetization value of our maghemite nanocomposite particle is lower than the value for bulk maghemite. It is worth noting that the temperature used in our experiments, $310 \mathrm{~K}$, matching the physiological body temperature $\left(37^{\circ} \mathrm{C}\right)$, is relatively high and is rarely investigated. Regarding the susceptibility, attainable through the initial rising part of the curve, i.e., the virgin curve of our hysteresis loop measurement, we obtained a specific "intrinsic" mass susceptibility, $\chi_{\mathrm{im}}=3.8 \times 10^{-4} / \mathrm{kg}$ of magnetic seeds (in the SI system, which in the CGS system gives $3.0 \times 10^{-2} / \mathrm{g}$ of magnetic seeds in the implant by dividing by a conversion factor of $\left.4 \pi \times 10^{-3}\right)$, after the deduction of the paramagnetic contributions (which represent a mass "paramagnetic" susceptibility of $5 \times 10^{-5} / \mathrm{kg}$ of magnetic seeds in SI, or $4 \times 10^{-3} / \mathrm{g}$ magnetic seeds in CGS). As previously discussed, $\chi_{\mathrm{im}}$ can be attributed to the iron oxide mass fraction, leading finally to a susceptibility of $1.9 \times 10^{-3} / \mathrm{kg}$ of iron oxide in the SI system (i.e., $0.15 / g$ of iron oxide in the CGS system).

\subsection{Magnetic properties of implants (SQUID)}

The static magnetic properties of in-situ-formed implants based on the two formulations, hydrogel (Alginate $2 \% \mathrm{w} / \mathrm{V}$ in water) or organogel (EVAL $8 \% \mathrm{w} / \mathrm{V}$ in DMSO), with increasing magnetic microparticle concentrations (whose compositions are detailed in Table 1 with respect to the methodological approach detailed in Section 2.3), appear to well correspond to the magnetic characteristics of the control magnetic particles. The hysteresis loops of all implants revealed similarities to those of the control sample (C), suggesting the preservation of the superparamagnetic behavior of microparticles in the implants formed in situ. It is important to note that the curves were even more similar when the magnetization values were weighted by the mass of constituting magnetic microparticles (or iron oxide content) determined on the basis of weighing the injections. This was not the case when the magnetization values were weighted by the masses of the wet implants introduced in the SQUID. The magnetic characteristics of the implants are summarized in Table 2, with respect to the magnetic characteristics of the control powder. As previously evaluated, the slope of $\mathrm{d} B / \mathrm{d} H$ after hysteresis enclosure was deduced. The calculated contributions to permeability per gram of wet sample increased with the magnetic microparticle concentration, reaching, for the formulation with the largest concentration of magnetic microparticles $(100 \% \mathrm{w} / \mathrm{v})$, half of the value measured for the control powder of magnetic microparticles. This deserves further comment. When looking at the weights of the injected formulations and of the wet implants introduced in the SQUID, we can exclude the effect of the alveolar water contained within the spongious microstructure of the implants (implant water contents ranged from $49 \%$ to $89 \%$, as also detailed in [35]). The magnetic effect of the polymer matrix should be considered, noting that the low polymer fraction decreases when the calculated contributions to permeability increase. It is likely that the matrix infiltrating micropores or the layer surrounding the particles, whose thickness decreases, would generate a permeability contribution opposed to the permeability contributions observed for the control. On the basis of an opposite contribution to permeability, one can also describe close associations of one constituent of the formulation or implant with the magnetic seeds of increasing mass fraction, likely involving the smallest porosities. We hypothesize that water,

Table 2

Magnetic characteristics determined by SQUID.

\begin{tabular}{|c|c|c|c|c|c|c|c|}
\hline Formulation & $\begin{array}{l}\text { Mass magnetic } \\
\text { susceptibility by kg of } \\
\text { sample as introduced in } \\
\text { SQUID (SI unit systems, } \\
\mathrm{m}^{3} \cdot \mathrm{kg}^{-1} \text { ) }\end{array}$ & $\begin{array}{l}\text { Deduced } \\
\text { contributions to } \\
\text { permeability per } \mathrm{kg} \\
\text { of sample }(\mathrm{SI} \mathrm{unit} \\
\left.\text { systems, } \mathrm{m}^{3} \cdot \mathrm{kg}^{-1}\right)\end{array}$ & $\begin{array}{l}\text { Coercive } \\
\text { field } \\
\left(\mathrm{A} \cdot \mathrm{m}^{-1}\right)\end{array}$ & $\begin{array}{l}\text { Retentivity per unit } \\
\text { mass of constituting } \\
\text { magnetic seeds } \\
\left(\mathrm{A} \cdot \mathrm{m}^{2} \cdot \mathrm{kg}^{-1} \text { or }\right. \\
\left.\mathrm{emu} \cdot \mathrm{g}^{-1}\right)\end{array}$ & $\begin{array}{l}\text { Mass magnetic } \\
\text { susceptibility per } \\
\text { unit mass of } \\
\text { constituting magnetic } \\
\text { microparticles }(\mathrm{SI} \text { unit } \\
\left.\text { systems, } \mathrm{m}^{3} \cdot \mathrm{kg}^{-1}\right)\end{array}$ & $\begin{array}{l}\text { Maximal magnetization } \\
\text { per unit mass of } \\
\text { constituting magnetic } \\
\text { seeds }\left(\mathrm{A} \cdot \mathrm{m}^{2} \cdot \mathrm{kg}^{-1} \text { or }\right. \\
\left.\mathrm{emu} \cdot \mathrm{g}^{-1}\right)\end{array}$ & $\begin{array}{l}\text { Hysteresis area per } \\
\text { unit mass of } \\
\text { constituting } \\
\text { magnetic } \\
\text { microparticles } \\
\left(\mathrm{A} \cdot \mathrm{m} \cdot \mathrm{kg}^{-1}\right)\end{array}$ \\
\hline O-05 & $3.01 \times 10^{-5}$ & $3.91 \times 10^{-6}$ & 248.933 & 0.11390 & $3.82 \times 10^{-4}$ & 2.9233 & 3638 \\
\hline $0-10$ & $5.66 \times 10^{-5}$ & $7.40 \times 10^{-6}$ & 239.543 & 0.11393 & $3.95 \times 10^{-4}$ & 3.0210 & 3669 \\
\hline $0-20$ & $9.02 \times 10^{-5}$ & $1.15 \times 10^{-5}$ & 238.120 & 0.11171 & $3.91 \times 10^{-4}$ & 3.0038 & 3606 \\
\hline $0-40$ & $1.38 \times 10^{-4}$ & $1.75 \times 10^{-5}$ & 253.278 & 0.11556 & $3.81 \times 10^{-4}$ & 2.8844 & 3602 \\
\hline $0-60$ & $1.59 \times 10^{-4}$ & $2.11 \times 10^{-5}$ & 266.589 & 0.11633 & $3.48 \times 10^{-4}$ & 2.7495 & 3654 \\
\hline $0-80$ & $1.68 \times 10^{-4}$ & $2.14 \times 10^{-5}$ & 259.233 & 0.10823 & $3.31 \times 10^{-4}$ & 2.6760 & 3480 \\
\hline $0-100$ & $1.82 \times 10^{-4}$ & $2.36 \times 10^{-5}$ & 246.423 & 0.10155 & $3.37 \times 10^{-4}$ & 2.5969 & 3533 \\
\hline $\mathrm{H}-05$ & $3.32 \times 10^{-5}$ & $4.31 \times 10^{-6}$ & 237.135 & 0.10942 & $3.89 \times 10^{-4}$ & 2.9489 & 3602 \\
\hline $\mathrm{H}-10$ & $4.71 \times 10^{-5}$ & $6.12 \times 10^{-6}$ & 227.949 & 0.10152 & $3.71 \times 10^{-4}$ & 2.8437 & 3156 \\
\hline $\mathrm{H}-20$ & $7.52 \times 10^{-5}$ & $1.01 \times 10^{-5}$ & 264.785 & 0.10128 & $3.05 \times 10^{-4}$ & 2.4570 & 3254 \\
\hline $\mathrm{H}-40$ & $1.30 \times 10^{-4}$ & $1.46 \times 10^{-5}$ & 301.299 & 0.11868 & $3.92 \times 10^{-4}$ & 2.5771 & 4172 \\
\hline $\mathrm{H}-60$ & $1.35 \times 10^{-4}$ & $1.71 \times 10^{-5}$ & 262.669 & 0.10916 & $3.29 \times 10^{-4}$ & 2.6575 & 3469 \\
\hline $\mathrm{H}-80$ & $1.67 \times 10^{-4}$ & $2.21 \times 10^{-5}$ & 255.879 & 0.10914 & $3.38 \times 10^{-4}$ & 2.6562 & 3518 \\
\hline $\mathrm{H}-100$ & $1.75 \times 10^{-4}$ & $2.30 \times 10^{-5}$ & 263.956 & 0.11505 & $3.50 \times 10^{-4}$ & 2.7822 & 3830 \\
\hline C & $4.28 \times 10^{-4}$ & $4.86 \times 10^{-5}$ & 307.428 & 0.11745 & $3.80 \times 10^{-4}$ & 2.6581 & 3776 \\
\hline
\end{tabular}


already present in the formulation for hydrogels or once precipitated in water for organogels, plays a prominent role in easily infiltrating the silica matrix and even the maghemite phase porosity. With a lower volume susceptibility, infiltrated water paramagnetism competes then with the silica diamagnetism. Regarding the coercivity, it should be restated that this parameter is only dependent on the microstructure and is related to the anisotropy. Similarly to an "intensive" magnetic property, coercivity is independent of the iron concentration [53]. In our case, the coercivity varied unpredictably for implants with increase in magnetic seed concentrations, but it remained constantly lower than or similar to the control powder. This indicates that there are no crucial anisotropy variations. Retentivity was also very comparable among the implants and control samples. The mass magnetic susceptibility and saturation magnetization of the implants were found here to be similar to those of control powder, and this was very concordant with the amount of magnetic seeds present in the implant. The hysteresis area (determined from the curves weighted by the amount of magnetic seeds constituting the implant) was reproducibly very constant. The small hysteresis area allows us to conclude that hysteresis losses would not significantly contribute to heating in AMF. Therefore, in hydrogel and organogel formulations forming in-situ implants, the magnetic properties of nanocomposite iron oxide silica microparticles, on which magnetically mediated hyperthermia in AMF relies, are relatively preserved.

\subsection{Heating capacities of implants under AMF}

Wet implant preparation conditions for SLP determinations were comparable to the conditions of preparation used for the magnetic property characterizations, with both conditions similar to the in vivo conditions. SLP was determined at $141 \mathrm{kHz}$ and $12 \mathrm{mT}$, per gram of iron oxide composing the implants by the two orthogonal methods: Methods A and B (see Sections 2.5.2 and 2.5.3, respectively). Of note, the sample characteristics and experimental details can be found in Tables 3 and 4, for experimental Methods $A$ and B, respectively. Results obtained by Methods A and B are gathered in Fig. 6. Taking all these results together and taking

Table 3

Sample details concerning Method A of SLP determination.

\begin{tabular}{|c|c|c|c|c|c|c|c|c|c|c|}
\hline Formulation & $\begin{array}{l}\text { Constituting } \\
\text { polymer in } \\
\text { the mother } \\
\text { solution }\end{array}$ & $\begin{array}{l}\text { Polymer } \\
\text { mass fraction } \\
\text { in the mother } \\
\text { solution }\end{array}$ & $\begin{array}{l}\text { Polymer mass } \\
\text { fraction in the } \\
\text { liquid } \\
\text { formulation }\end{array}$ & $\begin{array}{l}\text { Magnetic } \\
\text { microparticle } \\
\text { mass fraction } \\
\text { in the liquid } \\
\text { formulation }\end{array}$ & $\begin{array}{l}\text { Mean mass of the } \\
\text { liquid formulation } \\
\text { injected for } \\
\text { implantation (g) }\end{array}$ & $\begin{array}{l}\text { Variation } \\
\text { between } \\
\text { weighs in } \\
\text { mass } \\
\text { percentage }\end{array}$ & $\begin{array}{l}\text { Weight } \\
\text { of the } \\
\text { wet } \\
\text { implant } \\
\text { (g) }\end{array}$ & $\begin{array}{l}\text { Weight of } \\
\text { the } \\
\text { desiccated } \\
\text { implant }(\mathrm{g})\end{array}$ & $\begin{array}{l}\text { Mean } \\
\text { initial } \\
\text { implant } \\
\text { heating } \\
\text { rate }(\mathrm{K} / \mathrm{s})\end{array}$ & $\begin{array}{l}\text { Standard variation } \\
\text { of the measured } \\
\text { initial implant } \\
\text { heating rate }(\mathrm{K} / \mathrm{s})\end{array}$ \\
\hline O-05 & EVAL & 0.069 & 0.066 & 0.038 & 0.493 & 0.061 & 0.338 & 0.051 & 0.083 & 0.003 \\
\hline $0-10$ & EVAL & 0.069 & 0.064 & 0.079 & 0.569 & 0.105 & 0.456 & 0.080 & 0.158 & 0.099 \\
\hline $0-20$ & EVAL & 0.069 & 0.059 & 0.143 & 0.545 & 0.073 & 0.428 & 0.111 & 0.247 & 0.059 \\
\hline $0-40$ & EVAL & 0.069 & 0.052 & 0.248 & 0.521 & 0.019 & 0.423 & 0.155 & 0.317 & 0.049 \\
\hline $0-60$ & EVAL & 0.069 & 0.046 & 0.329 & 0.513 & 0.020 & 0.456 & 0.194 & 0.495 & 0.095 \\
\hline $0-80$ & EVAL & 0.069 & 0.042 & 0.392 & 0.559 & 0.161 & 0.512 & 0.240 & 0.646 & 0.046 \\
\hline $0-100$ & EVAL & 0.069 & 0.037 & 0.460 & 0.621 & 0.032 & 0.571 & 0.310 & 0.889 & 0.071 \\
\hline $\mathrm{H}-05$ & Alginate $\mathrm{Na}$ & 0.020 & 0.019 & 0.042 & 0.390 & 0.333 & 0.259 & 0.023 & 0.085 & 0.023 \\
\hline $\mathrm{H}-10$ & Alginate $\mathrm{Na}$ & 0.020 & 0.018 & 0.091 & 0.341 & 0.264 & 0.240 & 0.035 & 0.147 & 0.021 \\
\hline $\mathrm{H}-20$ & Alginate $\mathrm{Na}$ & 0.020 & 0.017 & 0.152 & 0.457 & 1.226 & 0.429 & 0.078 & 0.250 & 0.014 \\
\hline $\mathrm{H}-40$ & Alginate $\mathrm{Na}$ & 0.020 & 0.015 & 0.262 & 0.367 & 0.136 & 0.357 & 0.102 & 0.412 & 0.014 \\
\hline $\mathrm{H}-60$ & Alginate $\mathrm{Na}$ & 0.020 & 0.013 & 0.348 & 0.392 & 0.281 & 0.407 & 0.143 & 0.509 & 0.039 \\
\hline $\mathrm{H}-80$ & Alginate $\mathrm{Na}$ & 0.020 & 0.012 & 0.417 & 0.381 & 0.577 & 0.409 & 0.162 & 0.564 & 0.089 \\
\hline $\mathrm{H}-100$ & Alginate $\mathrm{Na}$ & 0.020 & 0.011 & 0.477 & 0.434 & 0.092 & 0.438 & 0.186 & 0.663 & 0.042 \\
\hline
\end{tabular}

Table 4

Sample details concerning Method B of SLP determination.

\begin{tabular}{|c|c|c|c|c|c|c|c|c|c|c|}
\hline Formulation & $\begin{array}{l}\text { Constituting } \\
\text { polymer in } \\
\text { the mother } \\
\text { solution }\end{array}$ & $\begin{array}{l}\text { Polymer mass } \\
\text { fraction in the } \\
\text { mother } \\
\text { solution }\end{array}$ & $\begin{array}{l}\text { Polymer mass } \\
\text { fraction in the } \\
\text { liquid } \\
\text { formulation }\end{array}$ & $\begin{array}{l}\text { Magnetic } \\
\text { microparticle mass } \\
\text { fraction in the } \\
\text { liquid formulation }\end{array}$ & $\begin{array}{l}\text { Mean mass of the } \\
\text { liquid formulation } \\
\text { injected for } \\
\text { implantation }(\mathrm{g})\end{array}$ & $\begin{array}{l}\text { Variation } \\
\text { between } \\
\text { weighs } \\
\text { in mass } \\
\text { percentage }\end{array}$ & $\begin{array}{l}\text { Weight } \\
\text { of the } \\
\text { wet } \\
\text { implant } \\
\text { (g) }\end{array}$ & $\begin{array}{l}\text { Weight } \\
\text { of the } \\
\text { desiccated } \\
\text { implant (g) }\end{array}$ & $\begin{array}{l}\text { Mean } \Delta T \\
\text { during } \\
2 \text { min in } \\
\operatorname{AMF}(K)\end{array}$ & $\begin{array}{l}\text { Standard } \\
\text { variation of } \\
\Delta T \text { during } \\
2 \text { min in } \\
\text { AMF }(K)\end{array}$ \\
\hline O-05 & EVAL & 0.069 & 0.066 & 0.038 & 1.012 & 0.040 & 0.714 & 0.104 & 0.678 & 0.203 \\
\hline $0-10$ & EVAL & 0.069 & 0.064 & 0.079 & 1.041 & 0.019 & 0.753 & 0.140 & 1.350 & 0.346 \\
\hline $0-20$ & EVAL & 0.069 & 0.059 & 0.143 & 1.121 & 0.036 & 0.896 & 0.227 & 3.827 & 0.808 \\
\hline $0-40$ & EVAL & 0.069 & 0.052 & 0.248 & 1.237 & 0.016 & 1.083 & 0.370 & 5.956 & 0.501 \\
\hline $0-60$ & EVAL & 0.069 & 0.046 & 0.329 & 1.328 & 0.038 & 1.166 & 0.508 & 10.782 & 1.514 \\
\hline $0-80$ & EVAL & 0.069 & 0.042 & 0.392 & 0.635 & 0.063 & 0.579 & 0.276 & 6.249 & 1.323 \\
\hline $0-100$ & EVAL & 0.069 & 0.037 & 0.460 & 1.090 & 0.073 & 1.034 & 0.366 & 10.119 & 0.561 \\
\hline $\mathrm{H}-05$ & Alginate $\mathrm{Na}$ & 0.020 & 0.019 & 0.042 & 0.950 & 0.105 & 0.722 & 0.058 & 0.761 & 0.351 \\
\hline $\mathrm{H}-10$ & Alginate $\mathrm{Na}$ & 0.020 & 0.018 & 0.091 & 1.037 & 0.617 & 0.902 & 0.105 & 1.322 & 0.153 \\
\hline $\mathrm{H}-20$ & Alginate $\mathrm{Na}$ & 0.020 & 0.017 & 0.152 & 0.553 & 0.887 & 0.504 & 0.095 & 1.142 & 0.602 \\
\hline $\mathrm{H}-40$ & Alginate $\mathrm{Na}$ & 0.020 & 0.015 & 0.262 & 0.746 & 0.496 & 0.740 & 0.206 & 4.529 & 0.237 \\
\hline $\mathrm{H}-60$ & Alginate $\mathrm{Na}$ & 0.020 & 0.013 & 0.348 & 1.211 & 0.025 & 1.331 & 0.427 & 8.215 & 0.462 \\
\hline $\mathrm{H}-80$ & Alginate $\mathrm{Na}$ & 0.020 & 0.012 & 0.417 & 1.048 & 0.114 & 1.147 & 0.435 & 9.639 & 0.964 \\
\hline $\mathrm{H}-100$ & Alginate $\mathrm{Na}$ & 0.020 & 0.011 & 0.477 & 0.796 & 0.000 & 0.870 & 0.538 & 10.430 & 1.408 \\
\hline
\end{tabular}




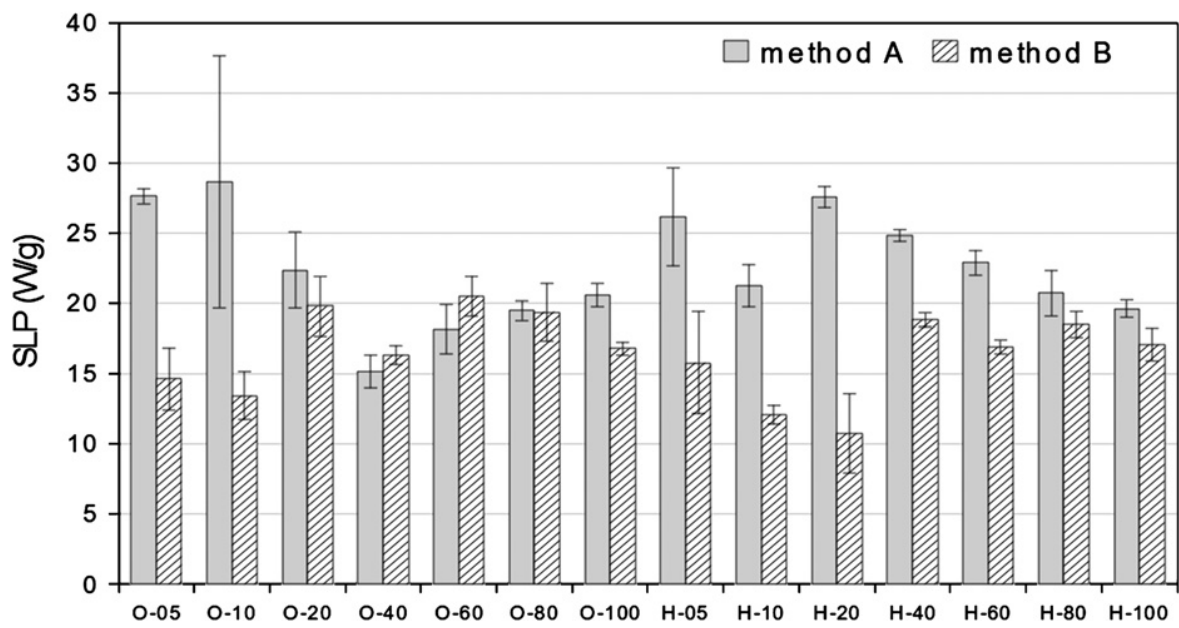

Fig. 6. Specific Loss Power (SLP) in W/g of iron oxide contained in the wet implants formed from various formulations with increasing magnetic $\gamma \mathrm{Fe}_{2} \mathrm{O}_{3}$ nanocomposite silica microparticles when submitted to an alternating magnetic field $(141 \mathrm{kHz}, 12 \mathrm{mT})$ and as determined by the two methods as described in the Section 2.5 . Method A, gray bars, is based on the initial temperature increase of the implant; Method B, hatched bars, is based on the temperature elevation of ca. 4 ml of water in contact with implant, as adapted from Bretcanu et al. (Acta Biomaterialia 1 (2005) 421-429) [43]. Sample details can be found in Tables 3 and 4 . The experiments were run in triplicates, except for H-40 with Method A (duplicate)

variability in account, it appears that the intrinsic SLP associated with magnetic seeds is preserved in the various implants studied here, with the real intrinsic SLP value tending to be the SLP value determined for the control particles, c.a. $20 \mathrm{~W} \mathrm{~g}^{-1}$ of iron oxide. From the pharmaceutical point of view, it should be mentioned that these formulations are also stable with regard to their magnetic properties and heating capacities over large periods of storage, and the limits of storage indeed rely on the loss of syringeability and implant formation capacity of the formulations (data not shown). With Method A, a short delay of a few seconds could be observed after switching on the AMF inducer before seeing a temperature increase. This delay could be attributed to the electromagnetic stabilization of the inducer. It could also result from the initial diffusion of heat in the implant (through thermal conductivity). The heat conduction through the silica matrix could be the limiting step in this case. Interestingly, when comparing both methods of SLP determination, it appears that Method A gives a poor precision for the implants containing low magnetic microparticle concentrations and likely associates with an overestimation of SLP. In contrast, Method B seems to be more precise at low magnetic microparticle fractions, but, regarding accuracy, the SLP seems underestimated in turn. For high magnetic microparticle concentrations, both methods appear to be relatively more accurate and precise, converging toward the SLP of c.a. $20 \cdot \mathrm{W} \mathrm{g}^{-1}$ of iron oxide contained in the implant. This strongly supports the preservation of the intrinsic SLP of the magnetic microparticles within the implants formed by both formulation types, even if slight differences can be suggested when precisely considering the effect of the polymer matrix. It is worth noting that with method $\mathrm{B}$, the temperature elevation in water reported as the mean $\Delta T$ in Table 4 gives an idea of the tissue temperature that could be reached in the ideal situation where no heat dissipation by convection or conduction occurs. As mentioned in the introduction, the most important parameter of heat dissipation is the blood flow and its response to heat under the pathophysiological conditions considered, which can eventually lead to negligible tissue temperature elevation in vivo. In this regard, it should be noted that both formulations are also known to be embolizing agents capable of blocking blood flow in vascular or tumor lesions, mainly when injected through intravascular routes but also when injected in solid tumors. The embolizing characteristics could contribute to increase the heating efficiency in situ and thereby increase the therapeutic potential [36].

\section{Conclusions}

The superparamagnetic properties of magnetic silica composite microparticles embedding nanoscaled maghemite iron oxides are preserved in the injectable formulations for the whole range of concentrations that allow syringeability. These properties also remain preserved in the implants formed in situ.

The magnetic properties as well as the heating capacity, which improved with increase in particle fraction, can be extrapolated from the concentration of magnetic microparticles. With these AMF parameters, a straightforward determination of the dissipated heat is now possible. In association with the previous in vivo studies, this further allows for the modeling of tissue heating in vitro and in vivo, and this improves our understanding of the heat delivery through formulations intended for magnetically mediated hyperthermia in the treatment of solid tumors.

\section{Acknowledgements}

Grant support: Swiss National Science Foundation (Grant 3200B0-104508), Switzerland. For TEM analysis, we are thankful to Mr Bauer Cristoph, Department of Zoology and Animal Biology, University of Geneva, Geneva, Switzerland. For MEB and EDX analysis, we are thankful to Mrs. Cravotto Géraldine, Department of Condensed Matter Physics, University of Geneva, Geneva, Switzerland.

\section{References}

[1] G.F. Baronzio, E.D. Hager, Hyperthermia in Cancer Treatment, Springer, 2006 [2] B. Hildebrandt, P. Wust, Cancer Treat. Res. 134 (2007) 171-184.

[3] G. Baronzio, G. Fiorentini, C.R. Cogle, Cancer Microenvironment and Therapeutic Implications: Tumor Pathophysiology Mechanisms and Therapeutic Strategies, Springer, 2009.

[4] G.F. Baronzio, A. Gramaglia, A. Baronzio, I. Freitas, Hyperthermia in Cancer Treatment, Springer, 2006, pp. 68-91.

[5] P.W. Vaupel, D.K. Kelleher, Thermoradiotherapy and Thermochemotherapy: vol. 1. Biology, Physiology, and Physics, Springer, 1995, pp. 159-176.

[6] P.W. Vaupel, D.K. Kelleher, Int. J. Hyperthermia (2010).

[7] D.K. Kelleher, P.W. Vaupel, Hyperthermia in cancer treatment, Springer, 2006 pp. 99-109.

[8] D.S. Latchman (Ed.), Stress Proteins, Springer, Berlin, 1999.

[9] G.C. Li, S.K. Calderwood, Int. J. Hypertherm. 25 (2009) 258-261.

[10] M.N. Rylander, Y. Feng, J. Bass, K.R. Diller, Ann. NY Acad. Sci. 1066 (2006) 222-242. 
[11] N.G. Theodorakis, D. Drujan, A. De Maio, J. Biol. Chem 274 (1999) 12081-12086.

[12] R.A. Coss, A.W. Sedar, S.S. Sistrun, C.W. Storck, P.H. Wang, P.R. Wachsberger, Int. J. Hypertherm. 18 (2002) 216-232.

[13] G. Multhoff, Handb Exp. Pharmacol. (2006) 279-304.

[14] A.D. Wells, M. Malkovsky, Immunol. Today 21 (2000) 129-132.

[15] V. Milani, E. Noessner, Cancer Immunol. Immunother. 55 (2006) 312-319.

[16] M.H. Manjili, X.Y. Wang, J. Park, I.J. Macdonald, Y. Li, R.C.A.A. Van Schie, J.R. Subjeck, Int. J. Hypertherm. 18 (2002) 506-520.

[17] J.J. Skitzki, E.A. Repasky, S.S. Evans, Curr. Opin. Invest. Drugs 10 (2009) $550-558$.

[18] E.J. Hall, A.J. Giaccia, Radiobiology for the Radiologist, Lippincott Williams \& Wilkins, 2006, pp. 469-490.

[19] M.H. Seegenschmiedt, P. Fessenden, C.C. Vernon, Thermoradiotherapy and Thermochemotherapy: vol. 1. Biology, Physiology, and Physics, Springer, 1995.

[20] M.N. Seegenschmiedt, P. Fessenden, C.C. Vernon, Thermoradiotherapy and Thermochemotherapy: vol. 2. Clinical applications, Springer Verlag, 1996.

[21] C.W. Song, Cancer Res. 44 (1984) 4721-4730.

[22] R.W.Y. Habash, R. Bansal, D. Krewski, H.T. Alhafid, Crit. Rev. Biomed. Eng. 34 (2006) 459-489.

[23] R.W.Y. Habash, R. Bansal, D. Krewski, H.T. Alhafid, Crit. Rev. Biomed. Eng. 34 (2006) 491-542.

[24] R. Hergt, W. Andrä, Magnetism in Medicine: A handbook, 2nd ed., Wiley-VCH, Weinheim, 2007, p. 550

[25] W. Andrä, U.O. Häfeli, R. Hergt, R. Misri, in: H. Kronmüller, S.S.P. Parkin (Eds.), Handbook of Magnetism and Advanced Magnetic Materials, John Wiley \& Sons, 2007, pp. 2460-2492.

[26] S. Dutz, R. Hergt, J. Mürbe, R. Müller, M. Zeisberger, W. Andrä, J. Töpfer, M. Bellemann, J. Magn. Magn. Mater. 308 (2007) 305-312.

[27] R. Hergt, S. Dutz, M. Roder, J. Phys.: Condens. Matter 20 (2008) 385214.

[28] A. Jordan, K. Maier-Hauff, P. Wust, M. Johannsen, Nanomaterials for Cancer Therapy, Wiley-VCH, Weinheim, 2006.

[29] A. Jordan, P. Wust, H. Fähling, W. John, A. Hinz, R. Felix, Int. J. Hypertherm. 9 (1993) 51-68.

[30] P. Wust, U. Gneveckow, M. Johannsen, D. Böhmer, T. Henkel, F. Kahmann, J. Sehouli, R. Felix, J. Ricke, A. Jordan, Int. J. Hypertherm. 22 (2006) 673-685.

[31] R. Hergt, W. Andra, C. d'Ambly, I. Hilger, W. Kaiser, U. Richter, H. Schmidt, IEEE Trans. Magn. 34 (1998) 3745-3754.
[32] R. Hergt, S. Dutz, J. Magn. Magn. Mater. 311 (2007) 187-192.

[33] B. Thiesen, A. Jordan, Int. J. Hypertherm. 24 (2008) 467-474.

[34] A.K. Gupta, R.R. Naregalkar, V.D. Vaidya, M. Gupta, Nanomedicine 2 (2007) 23-39.

[35] P. Le Renard, O. Jordan, A. Faes, A. Petri-Fink, H. Hofmann, D. Rüfenacht, F. Bosman, F. Buchegger, E. Doelker, Biomaterials 31 (2010) 691-705.

[36] P. Le Renard, F. Buchegger, A. Petri-Fink, F. Bosman, D. Rüfenacht, H. Hofmann, E. Doelker, O. Jordan, Int. J. Hypertherm. 25 (2009) 229-239.

[37] M. Chastellain, A. Petri, A. Gupta, K. Rao, H. Hofmann, Adv. Eng. Mater. 6 (2004) 235-241.

[38] B.D. Cullity, C.D. Graham, Introduction to Magnetic Materials, Wiley-IEEE, 2008.

[39] U. Schwertmann, Iron Oxides in the Laboratory: Preparation and Characterization, 2nd ed., Wiley-VCH, Weinheim, 2000.

[40] R.M. Cornell, The Iron Oxides: Structure, Properties, Reactions, Occurrence and Uses, VCH, Weinheim, 1996.

[41] P. Foladori, A. Quaranta, G. Ziglio, Water Res. 42 (2008) 3757-3766.

[42] J. Rodriguez-Carjaval, Full Prof. Suite, 2009.

[43] O. Bretcanu, S. Spriano, E. Verné, M. Cöisson, P. Tiberto, P. Allia, Acta Biomater. 1 (2005) 421-429.

[44] O. Bretcanu, E. Verné, M. Cöisson, P. Tiberto, P. Allia, J. Magn. Magn. Mater. 305 (2006) 529-533.

[45] R.H. Kodama, A.E. Berkowitz, J. McNiff, S. Foner, Phys. Rev. Lett. 77 (1996) 394.

[46] R.H. Kodama, J. Magn. Magn. Mater. 200 (1999) 359-372.

[47] P. Mollard, P. Germi, A. Rousset, Physica B+C 86-88 (1977) 1393-1394

[48] H. Batis-Landoulsi, P. Vergnon, J. Mater. Sci. 18 (1983) 3399-3403.

[49] C. Caizer, Phys. B: Condens. Matter 327 (2003) 27-33.

[50] C. Cannas, G. Concas, A. Musinu, G. Piccaluga, G. Spano, Z. Naturforsch. 54a (1999) 513-518.

[51] C. Cannas, G. Concas, F. Congiu, A. Musinu, G. Piccaluga, G. Spano, Z. Naturforsch. 57a (2002) 154-158.

[52] E. Tronc, D. Fiorani, M. Nogues, A.M. Testa, F. Lucari, F. D’Orazio, J.M. Greneche, W. Wernsdorfer, N. Galvez, C. Chaneac, D. Mailly, J.P. Jolivet, J. Magn. Magn. Mater. 262 (2003) 6-14.

[53] J.L. Wilson, J. Appl. Phys. 95 (2004) 1439. 